\title{
Self-Adaptive Control System for Additive Manufacturing Using Double Electrode Micro Plasma Arc Welding
}

\author{
Nan Li ${ }^{1}$, Ding Fan ${ }^{1,2^{*}}$, Jiankang Huang ${ }^{1,2^{*}}$, Shurong $\mathrm{Yu}^{2,3^{*}}$, Wen Yuan ${ }^{1}$ and Miaomiao Han ${ }^{1}$
}

\begin{abstract}
Wire arc additive manufacturing (WAAM) has been investigated to deposit large-scale metal parts due to its high deposition efficiency and low material cost. However, in the process of automatically manufacturing the high-quality metal parts by WAAM, several problems about the heat build-up, the deposit-path optimization, and the stability of the process parameters need to be well addressed. To overcome these issues, a new WAAM method based on the double electrode micro plasma arc welding (DE-MPAW) was designed. The circuit principles of different metaltransfer models in the DE-MPAW deposition process were analyzed theoretically. The effects between the parameters, wire feed rate and torch stand-off distance, in the process of WAAM were investigated experimentally. In addition, a real-time DE-MPAW control system was developed to optimize and stabilize the deposition process by self-adaptively changing the wire feed rate and torch stand-off distance. Finally, a series of tests were performed to evaluate the control system's performance. The results show that the capability against interferences in the process of WAAM has been enhanced by this self-adaptive adjustment system. Further, the deposition paths about the metal part's layer heights in WAAM are simplified. Finally, the appearance of the WAAM-deposited metal layers is also improved with the use of the control system.
\end{abstract}

Keywords: Double electrode microplasma arc welding, Additive manufacturing, Wire feed rate, Torch stand-off distance, Self-adaptive adjustment

\section{Introduction}

Additive manufacturing (AM) has gotten wide publicity in the aerospace, medical, and architecture fields as it allows the unlimited design for complex parts and the automated build process at low costs [1]. As one type of technologies in AM, wire arc additive manufacturing (WAAM) is popular with the fabrication of large metal components because of its potential for lowering material and equipment costs, improving the deposition rate,

\footnotetext{
*Correspondence: fand@lut.cn; sr2810@163.com; yushur1991@163.com

1 School of Materials Science and Engineering, Lanzhou University of Technology, Lanzhou 730050, China

${ }^{2}$ State Key Laboratory of Advanced Processing and Recycling of Non-ferrous Metals, Lanzhou University of Technology, Lanzhou 730050, China

Full list of author information is available at the end of the article
}

and producing metal parts with a theoretically unlimited build volume [2]. In addition, a wide variety of metal parts of materials ranging from steel and aluminum to titanium has been successfully deposited using this process, such as steel wind tunnel models and cones, aluminum wing ribs, and Ti-6Al-4V spars [3].

WAAM is mainly divided into three techniques by the type of welding processes that include gas metal arc welding (GMAW), gas tungsten arc welding (GTAW), and plasma arc welding (PAW) [4]. In GMAW-based WAAM, the wire is used as an electrode to produce an arc on the substrate, and the wire is filled into the melt pool through the arc from above [5]. However, the excessive heat input, the metal spatter, and the arc wandering are three unavoidable issues in GMAW-based WAAM deposition process, which adversely affects the size precision 
and quality of the thus-deposited parts [6]. To address these issues, many ongoing researches focus on temperature control techniques. But temperature variations are sensitive to the formation of the internal grain structure and the degree of plastic/elastic deformation. Therefore, the temperature control techniques are not suitable to improve the heat accumulation in GMAW-based WAAM deposition process, especially for depositing complex and large-sized metal parts. Yang et al. [7] analyzed the heat transfer behavior of GMAW-based WAAM by using an infrared camera system that needs the accurate calibration test. The results showed that increasing the cooling time of inter-layers did not effectively improve the accumulation phenomenon of heat in depositing metal parts but decrease the parts-making efficiency in some degree.

In GTAW-based WAAM, an electric arc is produce from the tungsten electrode to the substrate, and the wire is filled into the melt pool through the arc from the side [8]. This method can effectively avoid the arc wonder and the metal spatter and decrease the heat accumulation presented in GMAW-based WAAM deposition process. Furthermore, the arc formed during PAW is smaller than that produced during GTAW, which results in a narrower heat-affected zone and higher arc energy density. PAW-based WAAM processes are better than GTAWbased WAAM for depositing metal parts [9]. Compared with PAW, the current in the micro plasma arc welding (MPAW) can be adjusted to range from $0.01 \mathrm{~A}$ to 50 A to get narrower heat-affected zone and lower thermal build-up. Therefore, the micro plasma arc welding (MPAW)-based WAAM process had been introduced as an economic and energy-saving alternative for fabricating small and medium-sized metal parts as well as repairing high-value components [10].

Except for the selection of arc welding methods, several parts of the WAAM process have also been looked into by lots of researchers, including thermal build-up [11, $12]$, automated process planning $[13,14]$, and online process control [15]. Wu et al. [16] probed into the effects of thermal build-up on the deposited layers as well as the metal transfer behavior in depositing of Ti-6Al-4V parts by GTAW-based WAAM. The results showed that the surface oxidation of the interlayer as well as its temperature and geometry varied along the depositing direction, resulting in variations of the metal-transfer behavior. Bai et al. [17], designed a 3D numerical model to analyze the flow of the metal pool and heat transfer behaviors during the multilayer depositing process using PAWbased WAAM. They found that, as the number of the deposit layers increasing, the geometry of the metal pool changes, in which its width increases, while the height decreases.
For the automated process planning, Kumar et al. [18] developed a raster-based and perimeter-based tool path generation method for performing AM, in which the software MATLAB was used for algorithm implementation and the optimization of the tool path. Ding et al. [19] proposed a method named medial axis transformation (MAT) to provide the tool-paths for WAAM. Compared with the conventional contour patterns for depositing thin-walled parts, the deposited metal parts used MAT-based path planning strategy get the better performance and gap-free cross-sections. Venturini et al. [20] developed a feature-based computer-aided manufacturing software for depositing thin-walled components to improve its geometrical accuracy to ensure the required machining errors for the finishing operations.

For online process control techniques, Xiong et al. [21] designed a parameter adjusting system for GMAW-based WAAM to adjust the deposition rate to ensure that the layer heights of the deposited part remained constant. In the deposition process, a passive vision sensor system was used to test the distance from the nozzle to the top of the deposited parts. Dong et al. [22] put forward a method using Gaussian process regression and Bayesian optimization algorithm to model the continuous GTAW process and predict the geometry of the metal pool. In order to resolve the issue of poor corner accuracy during the fabrication of complex-shaped components by CMTbased WAAM, Li et al. [23] divided the depositing path into a few segments based on the features of the deposited parts and introduced a process control program by matching the travel speed with the depositing rate in each segment.

Above all, recent researches on WAAM have mainly focused on characterizing and evaluating the WAAM methods are available or not for depositing metal parts. Meanwhile, several researchers have respectively investigated online process control, automated process planning, and thermal build-up control [24]. However, in order to enhance the stability of the deposition process, geometric accuracy, and quality of the deposited parts, the development of WAAM techniques for metal parts, in particular, for fabricating large-scale structural parts and complex-shaped metal components, requires the integration of thermal build-up control, process planning, and online process control [25].

Fortunately, the micro plasma arc has several advantages for the heat producer of WAAM, such as high arc stiffness and energy density, small heat-affected zone, and a wide adjustment range of the power parameter [26]. In addition, the alternative use of non-transferred arc and transferred arc can improve the arc turn-on/off frequency in the process of MPAW-based WAAM. 
Given these merits of MPAW and double-electrode arc welding (DE-AW) $[27,28]$, in this study, we developed an innovative WAAM process that uses double electrode micro plasma arc welding (DE-MPAW) to ensure greater control over thermal build-up and the process stability. Meanwhile, a control platform based on an xPC Target system was used to optimize and control the DEMPAW-based WAAM deposition process. Furthermore, a control strategy was designed to simplify the process of planning the deposition paths on the deposited layers. The system was successfully used to deposit metal parts on complex-shaped substrates by varying the wire feed rate and torch stand-off distance real-time. Finally, several experiments were carried on to evaluate the performance of the control system.

\section{Materials and Methods}

The setup of the proposed DE-MPAW control system is presented in Figure 1. It includes a LHM-50 welding source, a WF-007b wire feeder, an AMR-300 resistance device, a CP-80 filming system, a 3-axes motion system and an $\mathrm{xPC}$ Target system. The $\mathrm{xPC}$ system is assembled by a host PC, a target PC, PCL-812PG and PCL-728 data acquisition devices, and Hall current-voltage sensors. CML-50 is a motion control device connected with the

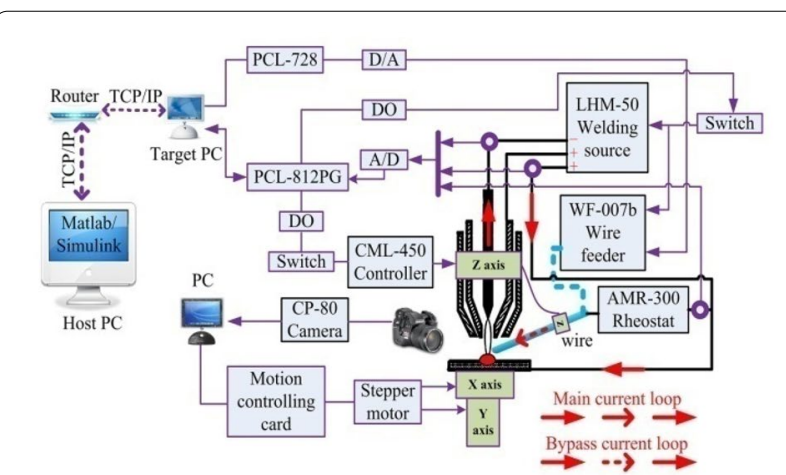

a Schematic of experimental setup

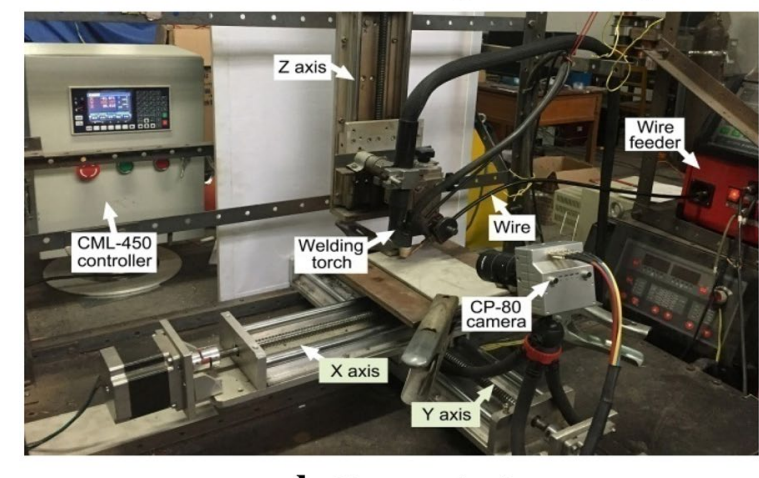

b Photograph of setup

Figure 1 Experimental setup of DE-MPAW control system
xPC system to independently control the $Z$ axe of the 3-axes motion system.

As depicted in Figure 1(a), the LHM-50 welding power source, which had a direct current range of $0.08-50 \mathrm{~A}$, is applied to make a constricted arc with negative polarity. The power source, electrode, and substrate form the main current loop. Meanwhile, the AMR-300 in series with the wire is added into the main circuit loop as a bypass part to control the heat flowing into the substrate. The data corresponding to the total and bypass currents are collected by the Hall sensors, while the data corresponding to the total and bypass voltages are collected by the voltage transmitter. Furthermore, based on the A/D conversion functionality of the PCL-812PG card, the analog data are individually converted into the digital data to be used as the input for the XPC Target system. The program of the control system can be designed in Matlab/Simulink on the host PC. This program needs be loaded into the target $\mathrm{PC}$ via the TCP/IP communication protocol to individually control WF-007b and CML-50 in order to ensure the appropriate wire feed rate and torch standoff distance. Meanwhile, the program can also be revised and modified real-time in Matlab/Simulink. The program outputs the analog signal corresponding to the wire feed rate from the PCL-728 multifunction data acquisition card to the WF-007b wire feeder to change the wire feed rate in real time.

To control the arc length, the welding torch and the wire added by the WF-007b feeder, are fixed together to the 3D-motion platform's $z$-axis. The application outputs ON-OFF signals from the PCL-812PG multifunction data acquisition card to CML-50 to automatically make the $z$-axis move up and down. Further, the substrate is clamped to the $x-y$ table of the 3D motion platform, which is controlled with a PC with a motion-controlling card to move the substrate along the $x$ - and $y$-axes.

\section{Self-Adaptive DE-MPAW Control System}

\subsection{Circuit Principle of DE-MPAW Control System}

Figure 2 shows the principle of the DE-MPAW system during the deposition process. The DE-MPAW system can be regarded as a circuit whose components are the micro plasma arc, substrate, deposited layers, feed wire, and rheostat. The micro plasma arc can be considered a special resistor $\left(R_{1}\right)$ whose current and voltage exhibit a nonlinear relationship and whose voltage is determined by the current and torch stand-off distance $(H)$. The substrate and deposited layers can together be considered as another resistor $\left(R_{2}\right)$. Finally, $R_{3}$ and $R_{4}$ are the wire and rheostat, respectively.

The main current $\left(I_{\text {main }}\right)$ is the current flowing through the deposited layers and substrate. The bypass current $\left(I_{\text {bypass }}\right)$ is the current flowing through the wire and 


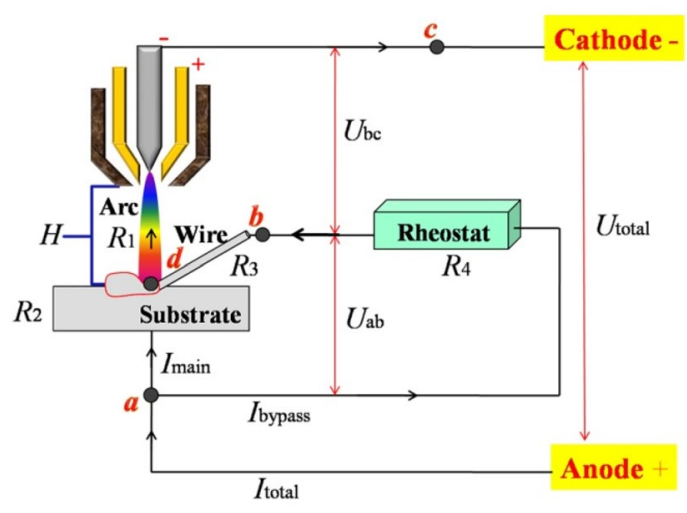

Figure 2 Relationship between voltage and current during DE-MPAW process

rheostat. $I_{\text {total }}$ is the total current, which can be set in the welding source panel of the micro plasma arc.

The total voltage $\left(U_{\text {total }}\right)$ is the voltage between the anode (point $a$ ) and cathode (point $c$ ), $U_{\text {arc }}$ refers to the voltage of the micro plasma arc, and the bypass voltage $\left(U_{\text {bypass }}\right)$ is the voltage between the anode and the left end of the wire (point $d$ ). Finally, $U_{\mathrm{ab}}$ represents the voltage of the rheostat. $I_{\text {total }}, I_{\text {bypass }}, U_{\text {total }}$, and $U_{\mathrm{ab}}$ can be measured readily using the voltage and current data acquisition system. Because the bypass voltage is difficult to measure, $U_{\mathrm{ab}}$ can be approximated as the bypass voltage in the DEMPAW system. The relationships between these parameters are as follows:

$$
\begin{aligned}
& I_{\text {main }}=I_{\text {total }}-I_{\text {bypass }}, \\
& U_{\text {bypass }}=I_{\text {bypass }}\left(R_{3}+R_{4}\right), \\
& U_{\text {bypass }} \approx U_{\text {ab }}=I_{\text {bypass }} R_{4} .
\end{aligned}
$$

\subsection{Effects of Wire Feed Rate and Torch Stand-off Distance}

The maximum wire feed rate plays a key role in the efficient deposition of metal parts. In order to measure the maximum wire feed rate corresponding to the different total currents and torch stand-off distances, single-pass weld deposition experiments were performed. Using the CP-80 camera, the maximum rate was determined by recording the wire feed rate of the wire feeder when the wire was about to extend outside the melt pool. The current and voltage data were collected using the XPC Target system shown in Figure 1. A specimen of the austenitic stainless steel 304 with dimensions of $200 \mathrm{~mm} \times 100$ $\mathrm{mm} \times 3 \mathrm{~mm}$ was used as the substrate. The deposited material was a welding wire of the stainless steel 304L with a diameter of $0.8 \mathrm{~mm}$. The chemical compositions of the substrate and deposited wire are shown in Table 1.

The various processing parameters and their ranges used in this study are presented in Table 2 . The values of the travel speed $(v)$, plasma orifice gas flow rate $\left(L_{1}\right)$, shield gas flow rate $\left(L_{2}\right)$, and wire feeding angle $(\theta)$ were kept constant. The total current was varied from $25 \mathrm{~A}$ to $50 \mathrm{~A}$ in intervals of $5 \mathrm{~A}$, while the torch stand-off distance ranged from $5 \mathrm{~mm}$ to $8 \mathrm{~mm}$ in intervals of $1 \mathrm{~mm}$. The wire feed rate $\left(V_{\mathrm{s}}\right)$, and total voltage $\left(U_{\text {total }}\right)$ were the parameters to be measured. The welding source power $(P)$ was the parameter to be calculated. A total of 24 experiments were performed, as shown in Table 3.

The metal-transfer models for various total currents and torch stand-off distances when the wire feed rate is the highest is shown in Figure 3. It is clear that, irrespective of the total current and torch stand-off distance, the bridging-transfer model corresponds to the highest wire feed rate. The top two pictures show that, when the total current is kept constant, the wire feed rate increases with the torch stand-off distance. The bottom two pictures show that, when the torch stand-off distance is kept constant, the wire feed rate increases with the total current. Finally, the images in the left and right columns show that the effect of the total current on the wire feed

Table 2 Processing parameters and their ranges

\begin{tabular}{ll}
\hline Parameter & Values \\
\hline Total current $I_{\text {total }}(\mathrm{A})$ & $25,30,35,40,45,50$ \\
Travel speed $v(\mathrm{~mm} / \mathrm{min})$ & 80 \\
Torch stand-off distance $H(\mathrm{~mm})$ & $5,6,7,8$ \\
Plasma orifices gas flow rate $L_{1}(\mathrm{~L} / \mathrm{min})$ & 1.0 \\
Shield gas flow rate $L_{2}(\mathrm{~L} / \mathrm{min})$ & 10.0 \\
Wire feeding angle $\theta\left(^{\circ}\right)$ & 60 \\
Weld source power $P(\mathrm{~W})$ & To be calculated \\
Total voltage $\left(U_{\text {total }}(\mathrm{V})\right.$ & To be measured \\
Wire feed rate $V_{\mathrm{s}}(\mathrm{cm} / \mathrm{min})$ & To be measured \\
\hline
\end{tabular}

Table 1 Chemical compositions (wt\%) of substrate and deposited material

\begin{tabular}{lllllllrr}
\hline Elements & C & Si & Mn & P & S & Cr & Ni & Fe \\
\hline Substrate & 0.07 & 0.47 & 1.12 & 0.02 & 0.03 & 18.50 & 8.25 & Bal. \\
Deposited material & 0.06 & 0.30 & 2.00 & 0.03 & 0.02 & 19.00 & 11.00 & Bal. \\
\hline
\end{tabular}


Table 3 Sets of processing parameters and their respective outcomes

\begin{tabular}{llllrl}
\hline Experiment ID & $\boldsymbol{H}(\mathbf{m m})$ & $\boldsymbol{I}_{\text {total }}(\mathbf{A})$ & $\boldsymbol{U}_{\text {total }}(\mathbf{V})$ & $\boldsymbol{P}(\mathbf{W})$ & $\boldsymbol{V}_{\mathbf{s}}(\mathbf{c m} / \mathbf{m i n})$ \\
\hline 1 & 5 & 25 & 21.34 & 526.03 & 117 \\
2 & 5 & 30 & 22.22 & 663.04 & 139 \\
3 & 5 & 35 & 23.13 & 806.08 & 158 \\
4 & 5 & 40 & 23.94 & 960.47 & 174 \\
5 & 5 & 45 & 24.72 & 1119.07 & 189 \\
6 & 5 & 50 & 24.71 & 1252.30 & 206 \\
7 & 6 & 25 & 22.49 & 559.32 & 128 \\
8 & 6 & 30 & 23.3 & 696.20 & 147 \\
9 & 6 & 35 & 24.49 & 851.52 & 168 \\
10 & 6 & 40 & 24.47 & 976.35 & 200 \\
11 & 6 & 45 & 25.4 & 1145.54 & 220 \\
12 & 6 & 50 & 25.53 & 1289.01 & 240 \\
13 & 7 & 25 & 23.02 & 568.36 & 135 \\
14 & 7 & 30 & 23.97 & 711.66 & 154 \\
15 & 7 & 35 & 24.53 & 855.36 & 176 \\
16 & 7 & 40 & 25.00 & 998.00 & 206 \\
17 & 7 & 45 & 25.70 & 1160.61 & 227 \\
18 & 7 & 50 & 26.21 & 1335.66 & 246 \\
19 & 8 & 25 & 23.89 & 590.32 & 123 \\
20 & 8 & 30 & 24.89 & 727.29 & 138 \\
21 & 8 & 35 & 25.64 & 895.86 & 157 \\
22 & 8 & 40 & 26.38 & 1055.50 & 179 \\
23 & 8 & 45 & 26.27 & 1188.70 & 199 \\
24 & 8 & 50 & 26.63 & 1343.20 & 231 \\
\hline
\end{tabular}

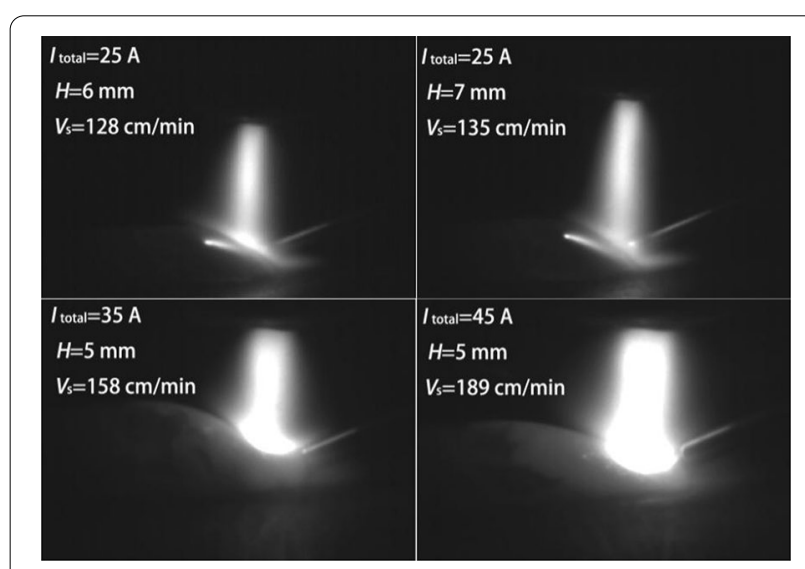

Figure 3 Metal-transfer modes corresponding to maximum wire feed rate

rate is more pronounced than that of the torch stand-off distance.

The metal-transfer models for various total currents and torch stand-off distances when the wire feed rate is the highest is shown in Figure 3. It is clear that, irrespective of the total current and torch stand-off distance, the bridging-transfer model corresponds to the highest wire feed rate. The top two pictures show that, when the total current is kept constant, the wire feed rate increases with the torch stand-off distance. The bottom two pictures show that, when the torch stand-off distance is kept constant, the wire feed rate increases with the total current. Finally, the images in the left and right columns show that the effect of the total current on the wire feed rate is more pronounced than that of the torch stand-off distance. The relationship between the total voltage and current for torch stand-off distances of 5, 6, 7, and $8 \mathrm{~mm}$ are depicted in Figure 4.

The total voltage increases with the current and torch stand-off distance, and these two parameters together determine the total voltage during the DE-MPAW deposition process. Based on the synergistic effects of the total current and torch stand-off distance on the total voltage, the following relationship for the total voltage is obtained:

$$
\begin{aligned}
& U_{\text {total }}=\varepsilon_{1} H+\varepsilon_{2} I_{\text {total }}+\varepsilon_{3} H \cdot I_{\text {total }}+\varepsilon_{4}, \\
& \boldsymbol{U}_{\text {total }}=\left[U_{i j}\right]_{4 \times 6}, \quad \boldsymbol{H}=\left[H_{i j}\right]_{4 \times 6}, \\
& \boldsymbol{I}_{\text {total }}=\left[I_{i j}\right]_{4 \times 6}, \quad \boldsymbol{H} \cdot \boldsymbol{I}_{\text {total }}=\left[H_{i j} \cdot I_{i j}\right]_{4 \times 6} .
\end{aligned}
$$

where index values of $i=1,2,3$, and 4 correspond to torch stand-off distances of $5,6,7$, and $8 \mathrm{~mm}$, respectively. Further, index values of $j=1,2,3,4,5,6$ represent total currents of $25,30,35,40,45$, and $50 \mathrm{~A}$, respectively.

Based on Eq. (4) and the parameter matrices given in Eq. (5) and Eq. (6), the following results can be obtained by linear fitting the total voltage data:

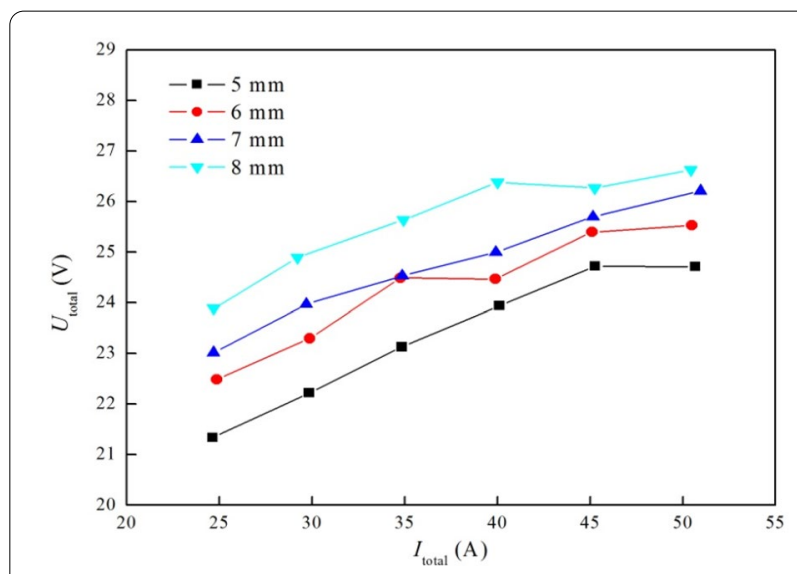

Figure 4 Relationships between total voltage and current for different torch stand-off distances 


$$
\begin{aligned}
& {\left[\begin{array}{ccccc}
1 & 0 & 37.5 & 0 \\
0 & 1 & 6.5 & 0 \\
6.5 & 0 & 0 & 1 \\
0 & 37.5 & 0 & 1
\end{array}\right] \times\left[\begin{array}{c}
\varepsilon_{1} \\
\varepsilon_{2} \\
\varepsilon_{3} \\
\varepsilon_{4}
\end{array}\right]=\left[\begin{array}{c}
0.73 \\
0.12 \\
19.82 \\
19.85
\end{array}\right],} \\
& \varepsilon_{1}>0.87, \quad \varepsilon_{2}>0.1382, \quad \varepsilon_{3}<0, \quad \varepsilon_{4}>0 .
\end{aligned}
$$

Furthermore, five sets of the coefficient matrix $(\varepsilon)$ could be calculated by Eq. (7) and Eq. (8), as shown below:

$$
\boldsymbol{\varepsilon}^{1}=\left[\begin{array}{c}
1.4 \\
0.236 \\
-0.018 \\
11.0175
\end{array}\right], \quad \boldsymbol{\varepsilon}^{2}=\left[\begin{array}{c}
1.8 \\
0.305 \\
-0.029 \\
8.4175
\end{array}\right], \quad \boldsymbol{\varepsilon}^{3}=\left[\begin{array}{c}
2.1 \\
0.357 \\
-0.037 \\
6.4675
\end{array}\right],
$$

$$
\boldsymbol{\varepsilon}^{4}=\left[\begin{array}{c}
2.5 \\
0.426 \\
-0.0472 \\
3.8675
\end{array}\right], \boldsymbol{\varepsilon}^{5}=\left[\begin{array}{c}
2.9 \\
0.496 \\
-0.058 \\
1.2675
\end{array}\right]
$$

The total voltage was determined by substituting the coefficient matrices $\boldsymbol{\varepsilon}^{1}, \boldsymbol{\varepsilon}^{2}, \boldsymbol{\varepsilon}^{3}, \boldsymbol{\varepsilon}^{4}$, and $\boldsymbol{\varepsilon}^{5}$ in Eq. (4). The error $\left(U_{\mathrm{e}}\right)$ between the experimentally determined and calculated total voltage values is shown in Figure 5.

Here, $\boldsymbol{E}_{\mathbf{m}}$ is the mean value of $U_{\mathrm{e}}$ corresponding to the different coefficient matrices, $\boldsymbol{\varepsilon}$, and $\boldsymbol{E}_{\mathbf{v}}$ is the variance of $U_{\mathrm{e}}$. Their values are given below:

$$
\begin{aligned}
& \boldsymbol{E}_{\mathrm{m}}=\left[\begin{array}{lllll}
-0.102 & -0.008 & -0.008 & -0.110 & -0.102
\end{array}\right], \\
& \boldsymbol{E}_{\mathbf{v}}=\left[\begin{array}{lllll}
0.304 & 0.333 & 0.371 & 0.434 & 0.513
\end{array}\right],
\end{aligned}
$$

The value of $\boldsymbol{E}_{\mathbf{m}}$ was the lowest (-0.008) for the coefficient matrices $\varepsilon^{2}$ and $\varepsilon^{3}$. Further, $\boldsymbol{E}_{\mathrm{v}}$ was 0.333 for $\boldsymbol{\varepsilon}^{2}$ and less than that for $\varepsilon^{3}$. Consequently, the total voltage calculated by Eq. (4) and the coefficient matrix $\varepsilon^{2}$ was in

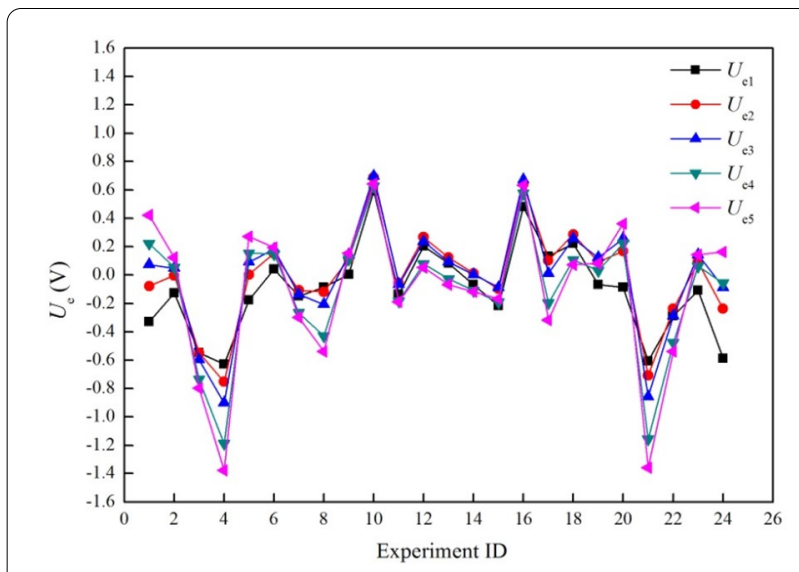

Figure 5 Error between experimentally determined and calculated total voltage values corresponding to different coefficient matrices keeping with the experimental data, and the equation for the total voltage could be written as

$$
U_{\text {total }}=1.8 H+0.305 I_{\text {total }}-0.029 H \cdot I_{\text {total }}+8.4175,
$$

The relationships between the calculated total voltage and total current for the different torch stand-off distances are shown in Figure 6.

Figure 7 shows the relationships between the torch stand-off distance, total current, and wire feed rate. With an increase in the total current from $25 \mathrm{~A}$ to $50 \mathrm{~A}$ in intervals of $5 \mathrm{~A}$, the curves for the relationship between the torch stand-off distance and wire feed rate changed dramatically. Thus, it can be concluded that the wire feed rate was sensitive to the torch stand-off distance at lower total currents.

In addition, for torch stand-off distances of 5, 6, 7, and $8 \mathrm{~mm}$, the wire feed rate increased with the total current.

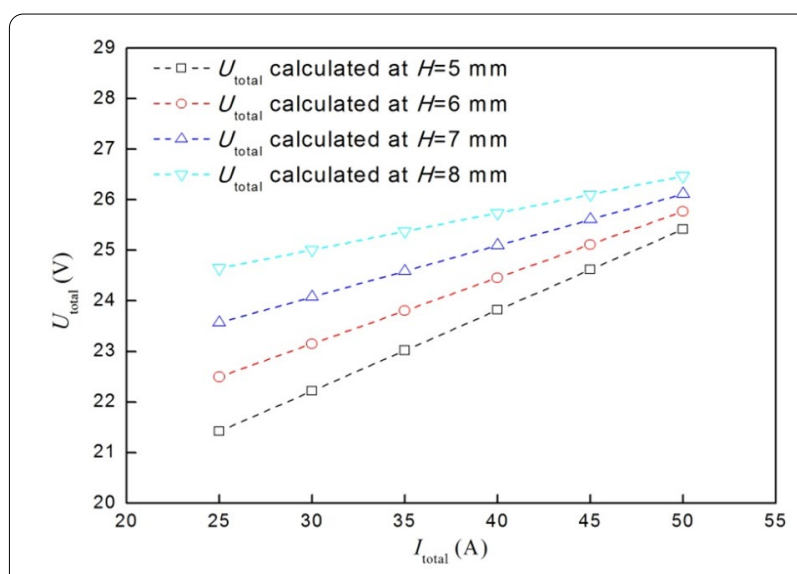

Figure 6 Relationships between calculated total voltage and total current for different torch stand-off distances

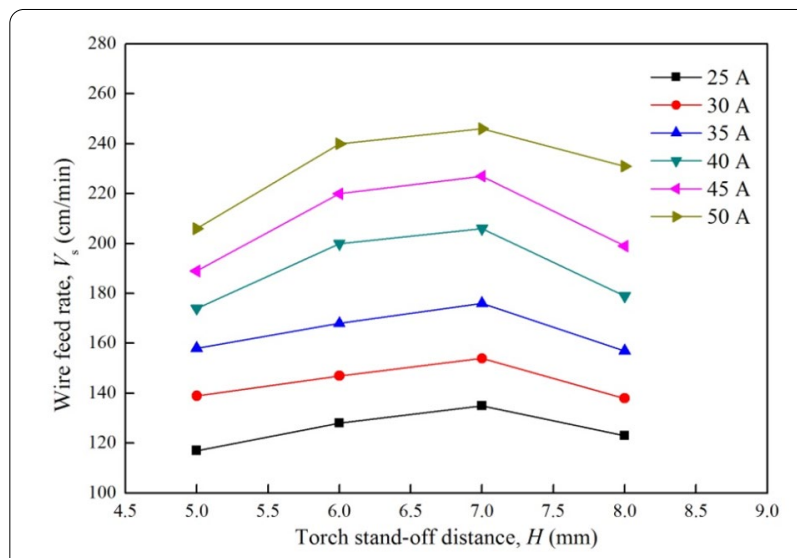

Figure 7 Relationships between wire feed rate and torch stand-off distance for different total currents 
Therefore, the torch stand-off distance and total current both affect the wire feed rate.

Furthermore, the total voltage is also determined by the torch stand-off distance and total current, as shown in Eq. (12). Besides, the wire feed rate is related to the amount of thermal energy available, and the weld source power is given by

$$
P=U_{\text {total }} \cdot I_{\text {total }},
$$

Thus, the wire feed rate is also related to the weld source power. The effect of the weld source power on the wire feed rate is shown in Figure 8.

The experimental data for the wire feed rate could be fitted using following linear function:

$$
V_{\mathrm{s}}=0.14 P+46.02 \text {. }
$$

\subsection{Effects of Bypass Voltage on Metal-Transfer Model}

Phenomena such as heat accumulation, mismatch in the wire feed rate, and arc wander during the WAAM deposition process lead to dynamic changes in the relative positions of the wire end and weld pool. Owing to these changes, the metal-transfer model switches between the bridge-transfer model and the droplet-transfer model. As a result, the circuit for the deposition process also switches dynamically between those corresponding to these two metal-transfer models.

When the wire end remains in contact with the weld pool through a liquid bridge during the deposition process, the valid metal-transfer model is the bridgingtransfer model. The DE-MPAW circuit in the case of the bridging-transfer model is shown in Figure 9.

On the other hand, when the wire extends into the weld pool, the micro plasma arc can be approximated by a

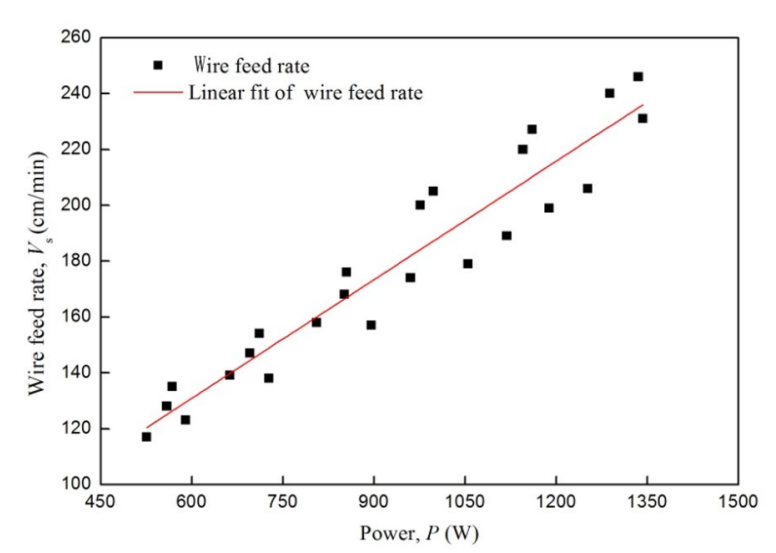

Figure 8 Relationship between wire feed rate and weld source power

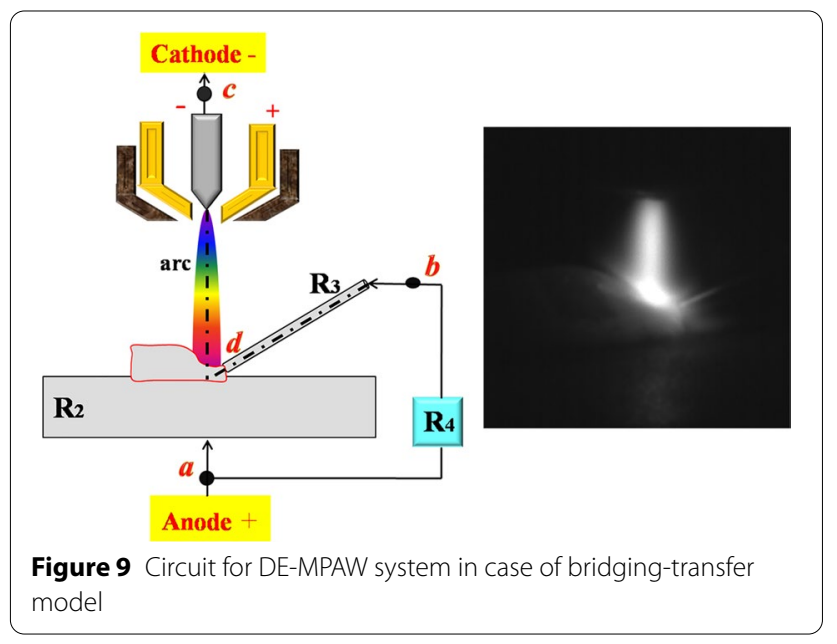

resistor in series with $R_{2}$. Meanwhile, $R_{2}$ is in parallel with $R_{3}$ and $R_{4}$, which constitute a parallel circuit. The equations for the circuit corresponding to the bridging-transfer model can be assumed to be the following:

$$
\begin{aligned}
& U_{\text {bypass }}^{1}=U_{\mathrm{ad}}=U_{\mathrm{R}_{2}}, \\
& I_{\text {bypass }}^{1}==\frac{U_{\text {bypass }}^{1}}{R_{3}+R_{4}},
\end{aligned}
$$

where $U_{\text {bypass }}^{1}$ and $I_{\text {bypass }}^{1}$ are the bypass voltage and current, respectively, in the circuit, and $U_{\text {ad }}$ is the voltage between the points $a$ and $d$.

If the torch stand-off distance increases by $\Delta H$ in the bridging-transfer mode, the wire end will extend into the micro plasma arc during the DE-MPAW deposition process. In this case, the metal is transferred into the welding pool in the droplet-transfer model, which is represented by a different circuit.

The circuit for the droplet-transfer model is shown in Figure 10. The micro plasma arc corresponding to $\Delta H$ micro plasma arc of $\Delta H$ is added to the main part of the circuit in series with $R_{2}$. As a result, the components of the parallel circuit are now the micro plasma arc corresponding to $\Delta H, R_{2}, R_{3}$, and $R_{4}$. The equations for the circuit corresponding to the droplet-transfer model are as follows:

$$
\begin{aligned}
& U_{\text {total }}^{2}=U_{\text {total }}^{1}+U_{\Delta \mathrm{H}}, \\
& U_{\text {bypass }}^{2}=U_{\text {ad }}=U_{\mathrm{R}_{2}}+U_{\Delta \mathrm{H}}, \\
& I_{\text {bypass }}^{2}=\frac{U_{\text {bypass }}^{2}}{R_{3}+R_{4}},
\end{aligned}
$$




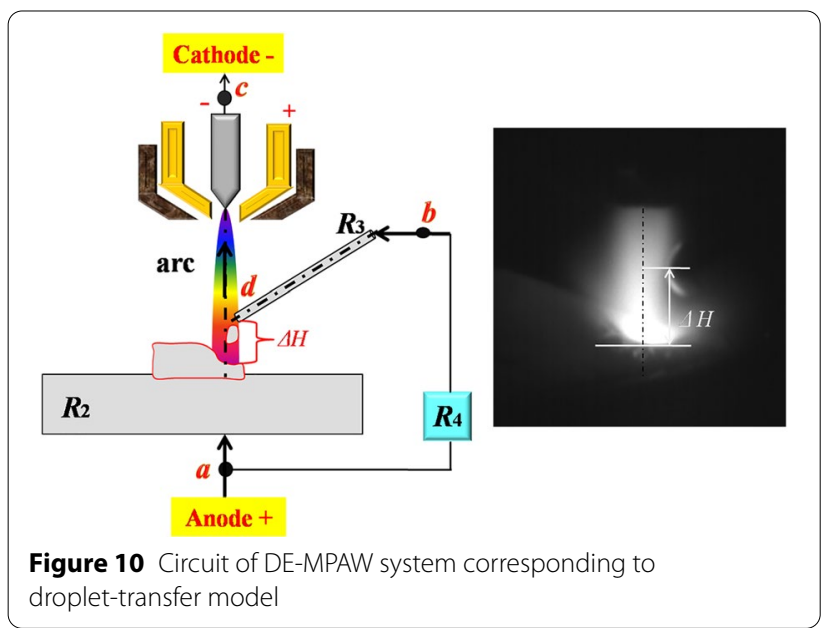

where $U_{\text {total }}^{1}$ is the total voltage in the circuit under the bridging-transfer model; $U_{\text {total }}^{2}$ is the total voltage in the circuit corresponding to the droplet-transfer model when the torch stand-off distance increases by $\Delta H ; U_{\text {bypass }}^{2}$ and $I_{\text {bypass }}^{2}$ are the bypass voltage and current, respectively, in the circuit for the droplet-transfer model when the torch stand-off distance increases by $\Delta H$; and $U_{\Delta \mathrm{H}}$ is the voltage drop of the micro plasma arc when the torch standoff distance increases by $\Delta H$.

Consequently, based on the voltage drop of the arc $\left(U_{\Delta \mathrm{H}}\right)$, the differences between the two circuits can be written as shown below:

$$
U_{\text {total }}^{2}>U_{\text {total }}^{1}, U_{\text {bypass }}^{2}>U_{\text {bypass }}^{1}, I_{\text {bypass }}^{2}>I_{\text {bypass }}^{1},
$$

In addition, if the wire feed rate decreases such that the wire end extends into the micro plasma arc, the circuit switches from the bridging-transfer circuit to the droplet-transfer circuit. In this case too, the micro plasma arc corresponding to $\Delta H$ is added to the main part of the circuit in series with $R_{2}$. The resistance of the wire, $R_{3}$, is lower than that in the bridging-transfer model. However, the torch stand-off distance remains unchanged. Thus, the differences between these two circuits can be written as shown below:

$$
U_{\text {total }}^{3}=U_{\text {total }}^{1}, U_{\text {bypass }}^{3}>U_{\text {bypass }}^{1}, I_{\text {bypass }}^{3}>I_{\text {bypass }}^{1},
$$

where $U_{\text {total }}^{3}, U_{\text {bypass, }}^{3}$ and $I_{\text {bypass }}^{3}$ are the total voltage, bypass voltage, and current, respectively, in the circuit corresponding to the droplet-transfer model when the wire feed rate decreases.

From Eq. (20) and Eq. (21), it is clear that whether the micro plasma arc corresponding to $\Delta H$ is caused by the torch stand-off distance or wire feed rate, the values of

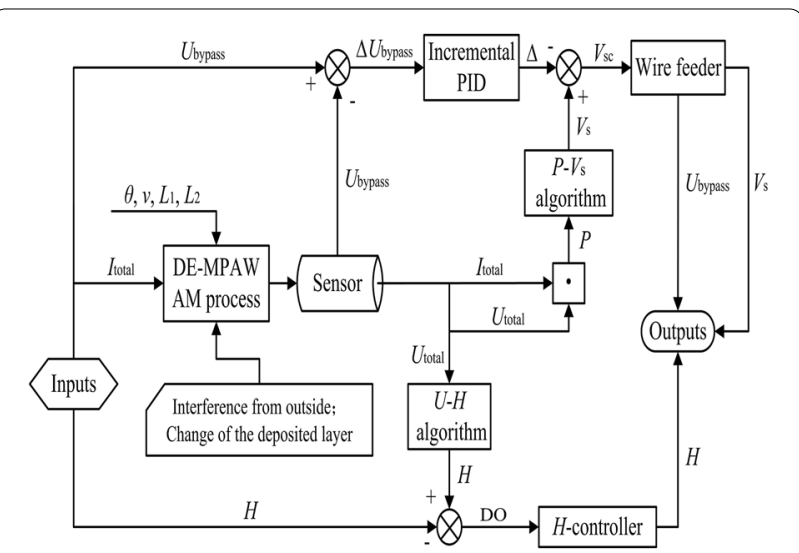

Figure 11 Structure of proposed DE-MPAW control system

$I_{\text {bypass }}$ and $U_{\text {bypass }}$ corresponding to the droplet-transfer model are larger than those in the bridging-transfer model. Therefore, both $I_{\text {bypass }}$ and $U_{\text {bypass }}$ can be used as indices to monitor the manner in which the metal is transferred into the welding pool.

\subsection{Self-Adaptive Control Model}

The bridging-transfer model can track higher wire feed rates to improve deposition efficiency. We used $U_{\text {bypass }}$ as an index to evaluate the transfer of the metal into the weld pool. The torch stand-off distance and wire feed rate have a determining effect on the manner in which the deposition material is transferred into the weld pool during the DE-MPAW process. Thus, controlling the torch stand-off distance and wire feeding rate is one way of ensuring stable and high-efficiency DE-MPAW AM.

Based on Eq. (12) and Eq. (14) and the effects of the bypass voltage on the metal-transfer models, we developed a DE-MPAW control system that self-adaptively adjusts the wire feed rate and torch stand-off distance.

A schematic of DE-MPAW control system is shown in Figure 11. Parameters, $v, \theta, L_{1}$, and $L_{2}$ are constants, and their values are listed in Table 2 . Further, $I_{\text {total }}, H$, and $U_{\text {by- }}$ pass, are the inputs of the control system while $H, V_{s}$, and $U_{\text {bypass }}$ are the outputs.

Input $U_{\text {bypass }}$ is the reference bypass voltage corresponding to the bridging-transfer model. Its value is determined by the initial values of $H$ and $I_{\text {total }}$. Parameters $U_{\text {bypass }}, I_{\text {total }}$, and $U_{\text {total }}$ can be measured real-time during the DE-MPAW process using sensors. In the case of outside interference or changes in the deposited layer during the deposition process, an error $\Delta U_{\text {bypass }}$, is inputted to the incremental PID controller, whose output is an increment $\Delta$. Based on the measured signals, $I_{\text {total }}$ and $U_{\text {total }}$, the power signal $P$, output is given by Eq. (12). Using the $P-V_{\mathrm{s}}$ algorithm described in Eq. (13), the corresponding 
wire feed rate, $V_{s}$, is determined. Simultaneously, the increment $\Delta$, is used to adjust the wire feed rate $V_{s}$, and decrease the error $\Delta U_{\text {bypass. }}$. Consequently, the adjusted wire feed rate is passed as the output to the wire feeder using the wire feed signal $V_{s c}$ which changes in real time through this self-adaptive adjustment process.

Meanwhile, based on the measured signal $U_{\text {total }}$, the torch stand-off distance $H$, is outputted by the $U$ - $H$ algorithm described in Eq. (12). Further, based on the selfadaptive adjustment range of $H$, the digital output (DO) signal is outputted to make the $H$-controller change the height of the welding torch real-time to stabilize $H$ over this range.

As shown in Figure 12, the self-adaptive DE-MPAW control system was implemented in the $\mathrm{xPC}$ Target realtime environment using the MATLAB/Simulink software platform. $H$ ranged from $5.8 \mathrm{~mm}$ to $6.2 \mathrm{~mm}$, and the initial value of $I_{\text {total }}$ was set to $35 \mathrm{~A}$. The reference bypass voltage corresponding to the bridging-transfer model was $1.92 \mathrm{~V}$.

With respect to the self-adaptive adjustment of $H$, if $H$ is less than $5.8 \mathrm{~mm}$, switch 1 turns on, and a signal for increasing $H$ is sent by output end 1 of the PCL-812 card to the CML-50 controller. As a result, the welding torch is made to move up automatically in order to increase $H$. However, if $H$ is larger than $6.2 \mathrm{~mm}$, switch 2 turns on and a signal to decrease $H$ is sent by output end 2 of the PCL-812 card to the CML-50 controller. In this case, the welding torch is controlled to move down automatically in order to decrease $H$.

For the self-adaptive adjustment of $V_{\mathrm{s}}, V_{\mathrm{s}}$ is outputted by the $P-V_{\mathrm{s}}$ algorithm program. Meanwhile, the error, $e(k)$, between the reference and measured values of $U_{\mathrm{by}-}$ pass is inputted to the incremental PID program, which outputs the increment $E(k) . E(k)$ is given by

$$
\begin{aligned}
& E(k)=E(k-1)+k_{\mathrm{i}} e(k)+k_{\mathrm{p}}[e(k)-e(k-1)] \\
& +k_{\mathrm{d}}[e(k)-2 e(k-1)+e(k-2)],
\end{aligned}
$$

where $k_{\mathrm{p}}$ is the constant of proportionality and has a value of $0.001 ; k_{\mathrm{i}}$ is the constant of integration and has a value of 0.005 ; and $k_{\mathrm{d}}$ is the constant of differentiation and has a value of 0.0025 .

If the measured $U_{\text {bypass }}$ is large than the reference voltage, the increment $E(k)>0$, and it is outputted to the wire feeder to increase $V_{s}$. However, if the measured $U_{\text {bypass }}$ is less than the reference value, $E(k)<0$, and the increment is outputted to the wire feeder to decrease $V_{s}$.

Finally, if the measured $U_{\text {bypass }}$ is equal to the reference voltage, $E(k)=0$, and $V_{\mathrm{s}}$ remains unchanged.

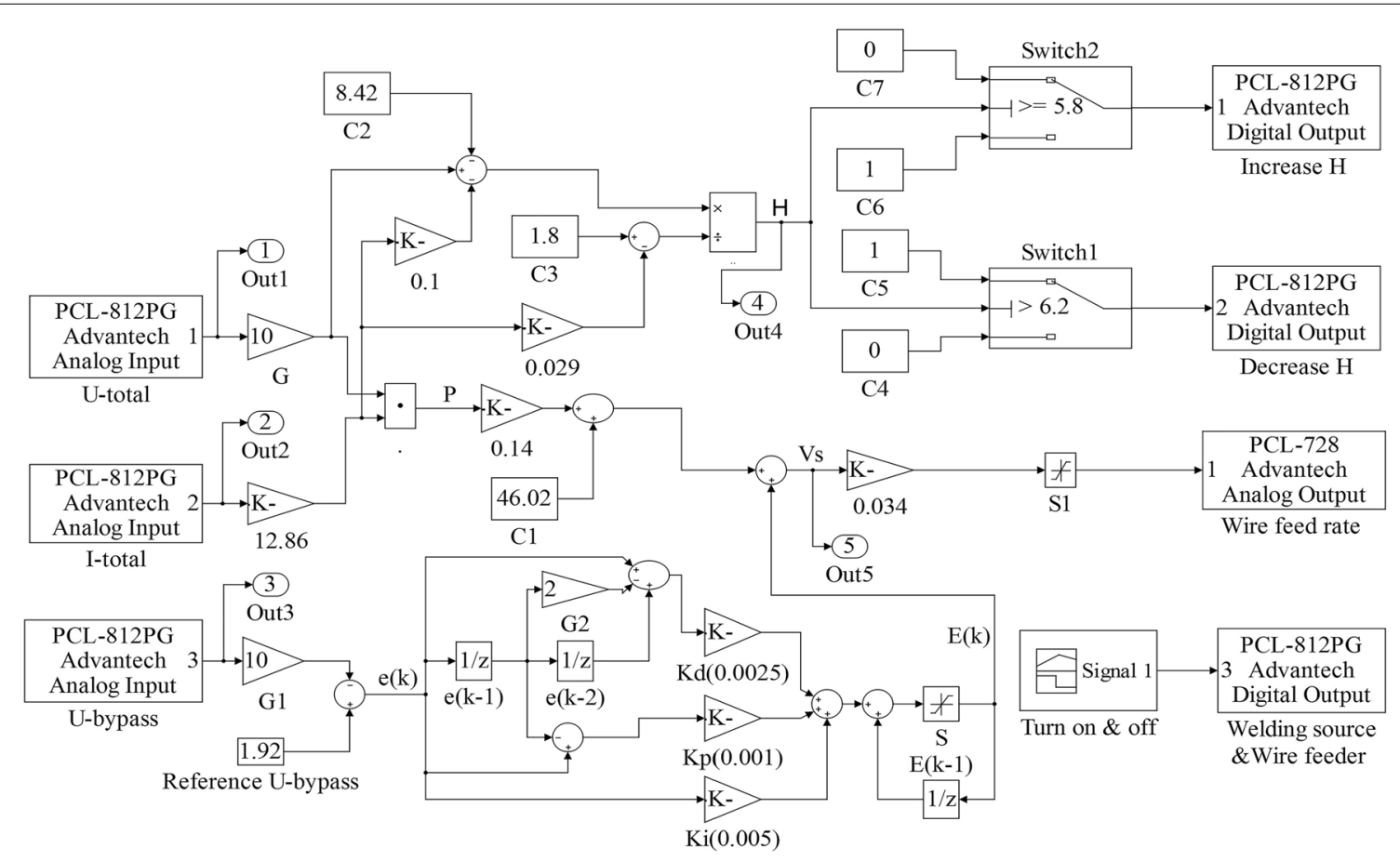

Figure 12 Diagram of self-adaptive DE-MPAW control system 


\section{Evaluation of Self-Adaptive DE-MPAW Control System}

Phenomena such as changes in the height of the deposited layer and overheating of the weld pool as well as cross-paths during the AM process adversely affect the final geometry and quality of the deposited parts. To evaluate the self-adaptive DE-MPAW control system, a series of tests were performed to verify the availability of the material to be deposited during the deposition process where in the height of deposition varied.

\subsection{Sloping-Substrate Test}

Two 304 austenitic stainless steel samples with dimensions of $200 \mathrm{~mm} \times 100 \mathrm{~mm} \times 3 \mathrm{~mm}$ were used to form a sloping substrate. The deposited material was a $304 \mathrm{~L}$ stainless steel welding wire with a diameter of $0.8 \mathrm{~mm}$. The chemical compositions of the substrate samples and deposited wire are listed in Table 1 . The total current, $I_{\text {to- }}$ tal, was $35 \mathrm{~A}$. The initial torch stand-off distance $H$, was 6 $\mathrm{mm}$, and it was limited to range from $5.8 \mathrm{~mm}$ to $6.2 \mathrm{~mm}$. Based on $I_{\text {total }}$ and $H$, the reference $U_{\text {bypass }}$ value was set at $1.92 \mathrm{~V}$. The values of the other parameters are presented in Table 2. A schematic of the process of depositing the molten 304L stainless steel solid wire on the sloping substrate is shown in Figure 13.

Position 1 in Figure 13 corresponds to the initial state of the deposition process during the sloping-substrate test; in this stage, $H$ was $6 \mathrm{~mm}$. In position 2, the welding torch is just above the top of the sloping substrate. In order to ensure than $H$ remains at $6 \mathrm{~mm}$ between positions 1 and 2, the welding torch is moved to a height of $6 \mathrm{~mm}$ along the ascending branch of the sloping substrate till position 2. From the position 2 to position 3 , the welding torch is moved gradually along the descending branch. In this manner, the sloping-substrate test was performed to evaluate the ability of the self-adaptive DEMPAW control system to track the continuous changes

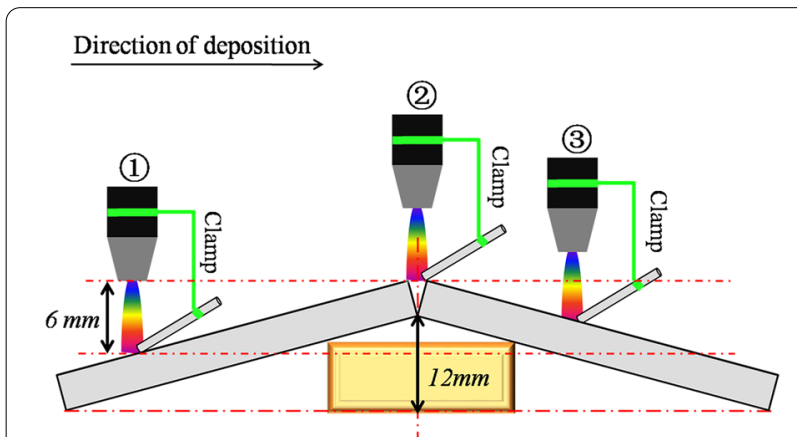

Figure 13 Schematic diagram of process of depositing molten wire material on sloping substrate in $H$ while depositing a metallic material on a complexshaped substrate.

As shown in Figure 14, a smooth and defect-less weld bead was deposited successfully on the sloping substrate using the control system. The changes in the torch standoff distance were determined based on photographs taken by the CP- 80 camera. At the $11.02 \mathrm{~s}$, the value of $H$ as the torch moved over the ascending branch of the sloping substrate was $5.2 \mathrm{~mm}$; at the $21.02 \mathrm{~s}$, the value of $H$ was $5.9 \mathrm{~mm}$, and the torch was above the top of the substrate; finally, at the $38.04 \mathrm{~s}$, the value of $H$ as the torch moved over the descending branch of the substrate was $6.5 \mathrm{~mm}$.

Furthermore, the real-time data of the torch stand-off distance and wire feed rate during the sloping-substrate test are shown in Figure 15.

The fluctuations in $H$ as the torch moved over the ascending branch were less than those in the case of

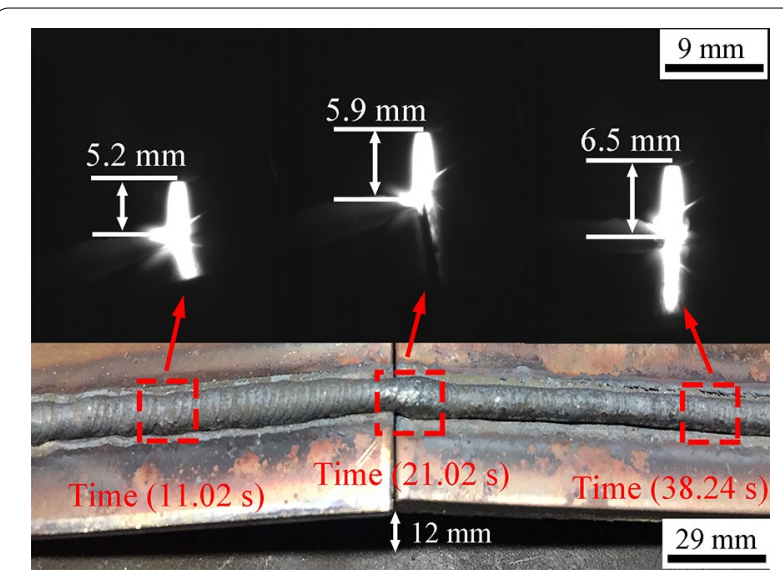

Figure 14 Changes in torch stand-off distance during sloping-substrate test

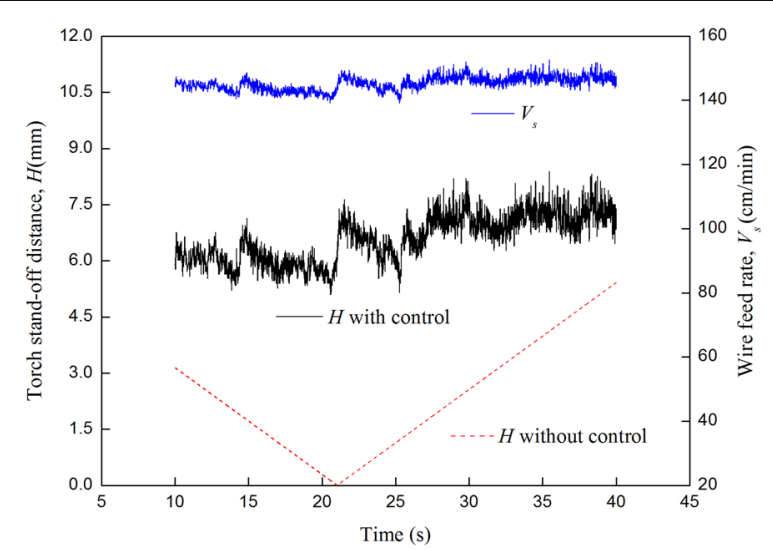

Figure 15 Total voltage and wire feed rate during sloping-substrate test 
the descending branch. Besides, the average value of $H$ is about $6.0 \mathrm{~mm}$ during the ascending branch while it is about $7.0 \mathrm{~mm}$ during the descending branch. The maximum average error of $H$ is about $1.0 \mathrm{~mm}$ happening in the descending branch.

However, if the welding torch were to move towards the top of the slope in the absence of a control system, the torch stand-off distance would decrease continuously and becomes zero at the top of the substrate. Moreover, the torch stand-off distance would gradually increase to $6.0 \mathrm{~mm}$ when moving down along the slop. This process of $H$ is shown and labeled as the " $H$ without control" in Figure 15.

In contrast, the $H$ fluctuations were significantly larger when the self-adaptive control system was used. This confirmed that the $H$ fluctuations can be effectively controlled by the self-adaptive control system during the entire sloping-deposition process. Besides, the control system still need to be improved to decreases the error of $\mathrm{H}$ during the deposition process in the descending branch.

\subsection{Tests Involving Deposition of Single-Walled Component and Metal Part in Form of Chinese Language Character}

To deposit a metal part in form of Chinese language character "中", the total current used was $35 \mathrm{~A}$, and the torch stand-off distance ranged from $4.8 \mathrm{~mm}$ to $5.2 \mathrm{~mm}$. Further, the reference bypass voltage corresponding to the bridging-transfer model was set at $1.6 \mathrm{~V}$. The values of the other parameter are presented in Table 2. The deposition paths for the Chinese character are presented in Figure 16.

In the case of the first path, the welding torch started from position 1 . The process of deposition was performed

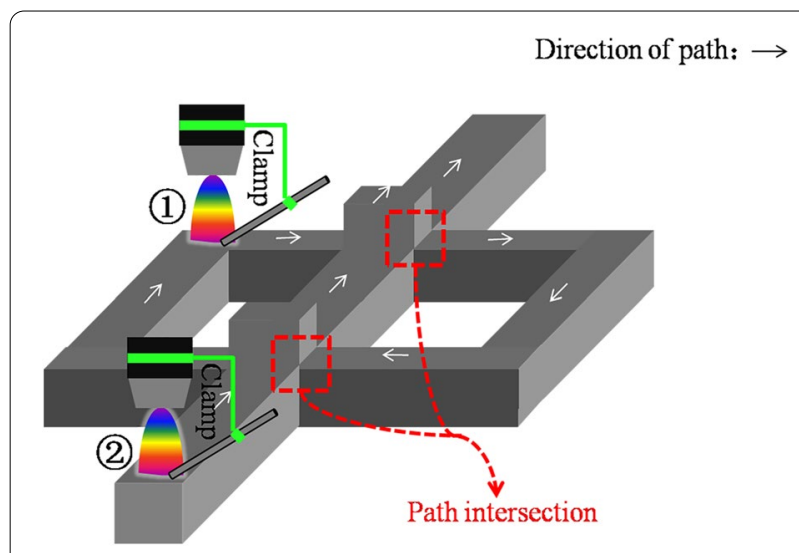

Figure 16 Schematic of depositing the metal material in form of Chinese characters using self-adaptive DE-MPAW control system in the clockwise direction, and the torch returned to position 2. For the second deposition path, the welding torch started from position 2 and deposited material directly across the first deposition path. Hence, this test included cross-paths, which pose a significant challenge during WAAM deposition.

As can be seen from Figure 17, the metal part in form of Chinese character "中" is successfully deposited by the self-adaptive DE-MPAW control system. The torch standoff distance and wire feed rate corresponding to the second deposition path are given in Figure 18. Compared to the case during the movement of the welding torch towards the path intersections in the absence of a control method, the fluctuations in the torch stand-off distance
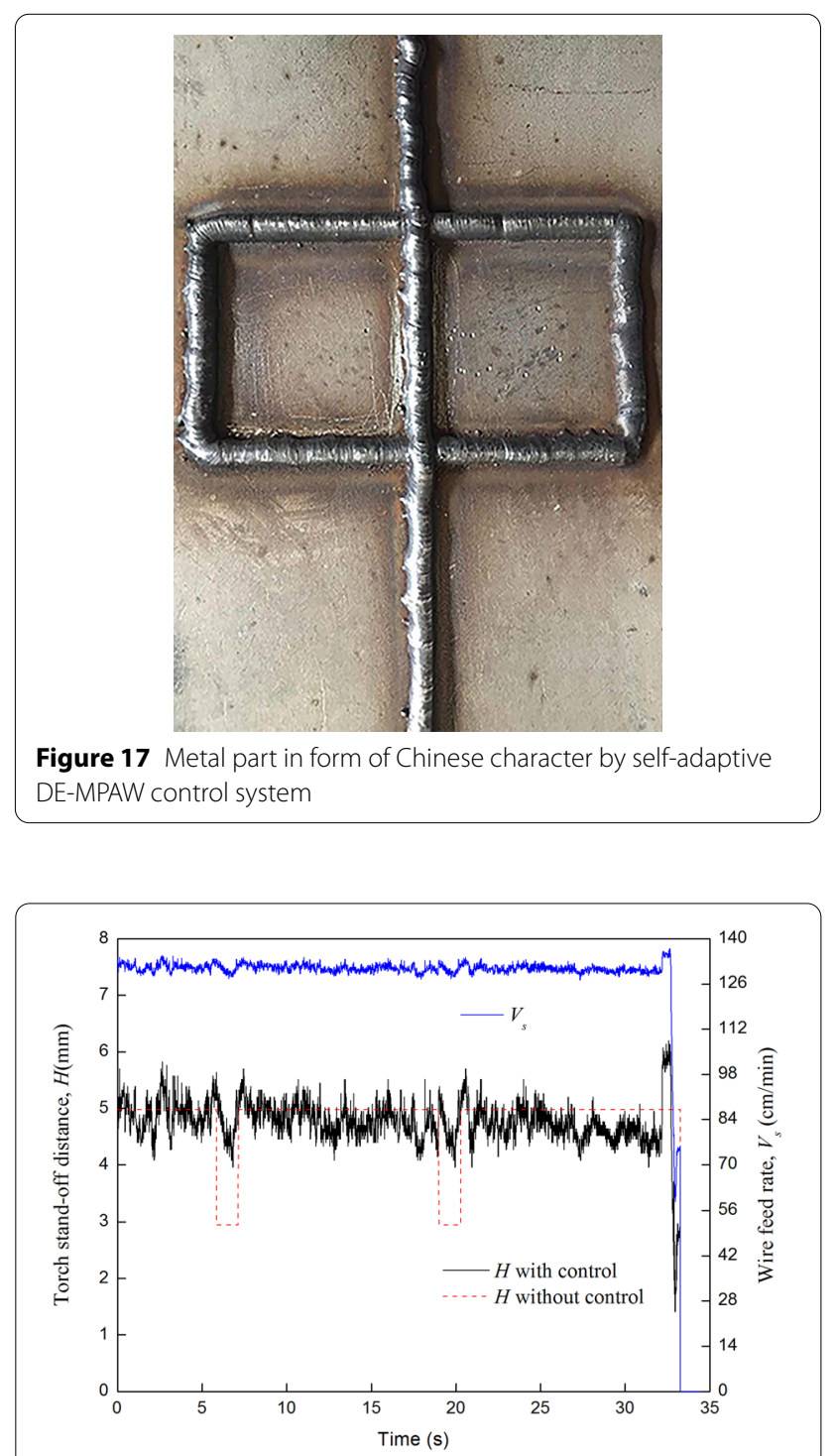

Figure 18 Voltage and wire feed rate for second deposition path 
when the self-adaptive control system was used were relatively smaller. In addition, the wire feeding rate was low when the torch moved across the path intersections.

The single-walled component is deposited to evaluate whether the self-adaptive DE-MPAW control system can make the design of the deposition path in height orientation simpler.

The total current was $35 \mathrm{~A}$, and the torch stand-off distance was set to range from $5.8 \mathrm{~mm}$ to $6.2 \mathrm{~mm}$. The reference $U_{\text {bypass }}$ value was $1.92 \mathrm{~V}$. The values of the rest of the parameters were the same as those in Table 2. The deposition paths for the single-walled component are shown in Figure 19. The single-walled component required the deposition of 20 layers, and the deposition direction of each layer had to be the alternating. Moreover, after the deposition of every layer, the welding torch had to be automatically adjusted to the next layer to ensure that the torch stand-off distance did not vary significantly.

The single-walled component consisting of 20 layers as deposited by the self-adaptive control system is shown in Figure 20.

While the part has a rough appearance, indicating that the accuracy of the control system needs to be improved further, it can be seen that the system could successfully deposit the multiple layers to form the component without significant variations in the deposition height. The issue of the collapse of single-walled components formed by WAAM processes could be overcome with the control system. This was because the amount of heat flowing into the deposited layers and the substrate is reduced by the bypass current loop, and the welding torch can move up and down automatically to track the deposited layers. This prevents outside interferences from affecting the arc length. Moreover, the control system allowed the twodimensional deposition process to be transformed into a

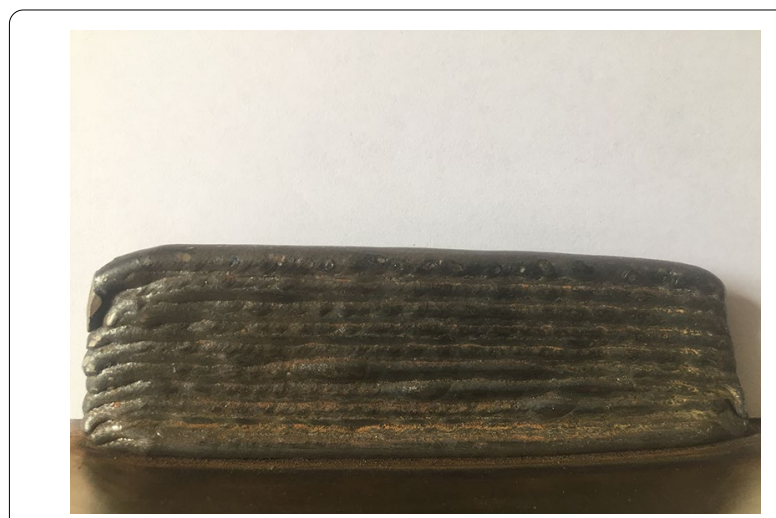

Figure 20 Single-walled component deposited using proposed self-adaptive control system

one-dimensional one with having to determine the final height of the deposited layers in advance.

The dynamic changes in the deposition parameters during the deposition of 1st-10th of the single-walled component are presented in Figure 21.

After the deposition of each layer, the main arc will turn off automatically for $2 \mathrm{~s}$ to make sure solidification of the molten pool before the next deposition. And the wire feed rate in the odd layers was set about $20 \mathrm{~cm} / \mathrm{min}$ higher than the even layers. Because the wire is filled into the front-end of molten pool in the deposition process of the odd layers, and filled into the back-end of molten pool in the deposition process of the even layers. The total voltage, and bypass current remained relatively constant during the deposition process of the first ten layers. The bypass current is about 0.5 times of total current, which means the heat flowed through the deposited layers and substrate is effectively reduced and improved.

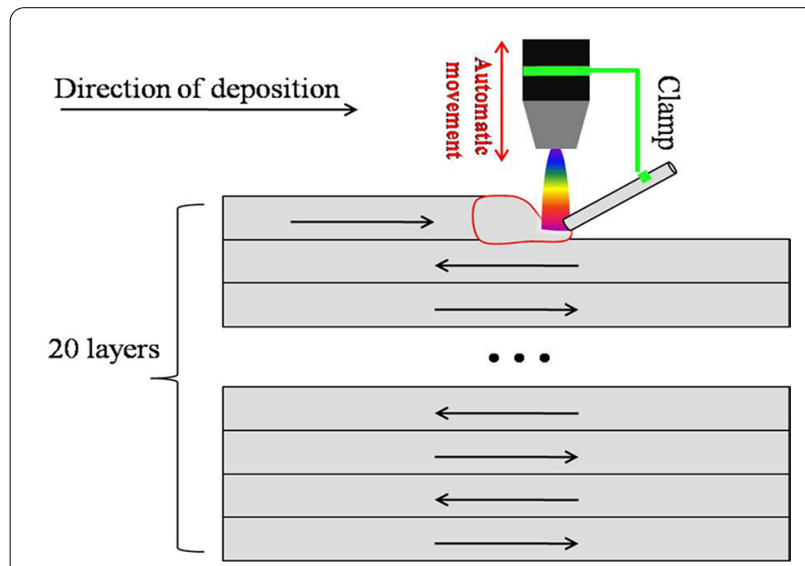

Figure 19 Schematic of deposition of single-walled component using proposed self-adaptive control system

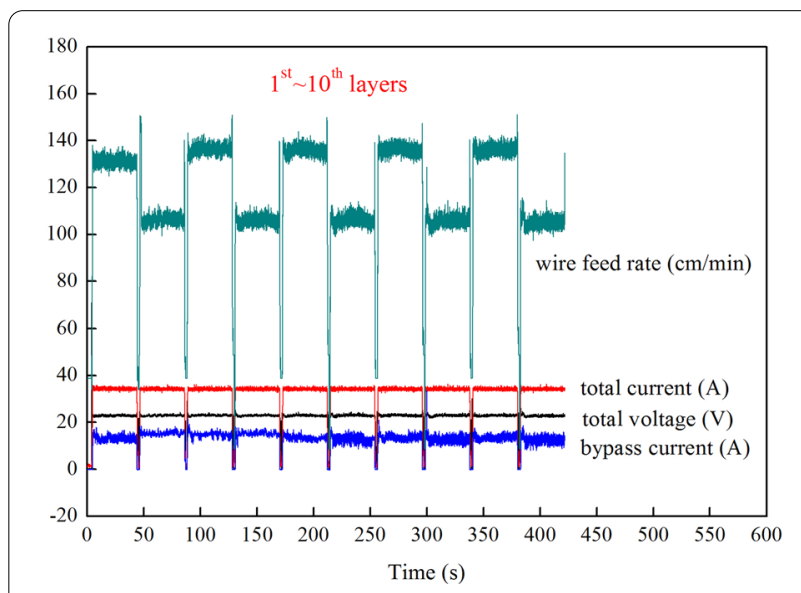

Figure 21 Parameters data collected in the deposition process of the 1st-10th layers 
As presented in Figure 22, the total voltage and bypass current also remain relatively constant in the deposition process of the last ten layers. But the wire feed rates are larger than the values in the deposition process of the first ten layers. One reason for this phenomenon is that, because of the heat accumulation,with an increase of the deposited layers, the width of molten pool become larger when the height of molten pool become lower, especially in the deposition process of the last ten layers. Therefore, by using the self-adaptive control system, the wire feed rate increased automatically in the last ten layers effectively made up for the liquid metal flowing away from the molten pool. The collapsed phenomenon of the deposited layers can also be improved by this self-adaptive control system.

\section{Conclusions}

In this study, we developed an innovative control system for AM via DE-MPAW and evaluated it using a series of deposition tests. The main conclusions of the study are presented as follows:

(1) For the DE-MPAW deposition process, the bridging-transfer model is the most suitable for ensuring a higher wire feeding rate to improve the deposition efficiency. Further, both the bypass current and the voltage can be used as indexes to evaluate metal transfer into the weld pool.

(2) Using the proposed self-adaptive DE-MPAW control system, we successfully deposited a metallic material on different-shaped substrates. Thus, it was confirmed that the system protects the deposition process of WAAM from the interferences of torch stand-off distance and this system can be

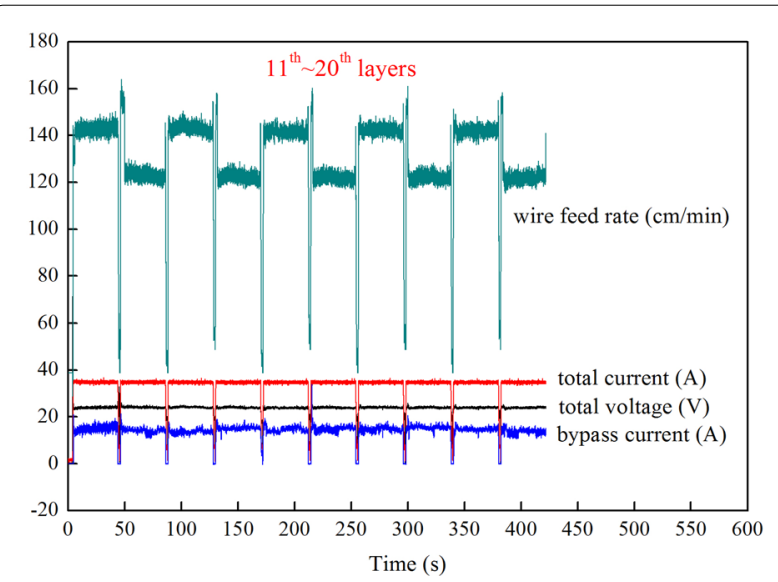

Figure 22 Parameters data collected in the deposition process of the 11th-20th layers potentially applied to repair of complex surface metal parts.

(3) The deposition path design of WAAM is simplified and optimized by automatically moving the welding torch up or down in the height direction of the deposited parts.

(4) The collapsing of the weld pool result from overheating during the WAAM process is improved. Because the heat input of the deposited layers and substrate is reduced by the bypass current and the control system can self-adaptively adjust the wire feed rate and torch stand-off distance real-time in the process of WAAM.

\section{Acknowledgements}

We are grateful for the technical and financial support provided by Lanzhou University of Technology, and National Natural Science Foundation of China.

\section{Authors' contributions}

$\mathrm{NL}$ wrote the manuscript; DF assisted in English translation; JH, SY, WY and $\mathrm{MH}$ assisted in numerical analysis and experimental verification. All authors read and approved the final manuscript.

\section{Authors' Information}

Nan Li, is currently a master degree candidate at Lanzhou University of Technology, China. His research interests include additive manufacturing.

Ding Fan, is currently a professor at Lanzhou University of Technology, China. His research interests include numerical simulation of welding and arc additive manufacturing.

Jiankang Huang, is currently an associate professor at Lanzhou University of Technology, China. His research interests include numerical simulation of welding and arc additive manufacturing.

Shurong Yu, is currently a professor at Lanzhou University of Technology, China. Her research interests include arc additive manufacturing.

Wen Yuan, is currently a master degree candidate at Lanzhou University of Technology, China. His research interests include additive manufacturing.

Miaomiao Han, is currently a master degree candidate at Lanzhou University of Technology, China. Her research interests include numerical simulation of welding and additive manufacturing.

\section{Funding \\ Supported by National Natural Science Foundation of China (Grant No. 51665034).}

\section{Competing Interests}

The authors declare no competing financial interests.

\section{Author Details}

${ }^{1}$ School of Materials Science and Engineering, Lanzhou University of Technology, Lanzhou 730050, China. ${ }^{2}$ State Key Laboratory of Advanced Processing and Recycling of Non-ferrous Metals, Lanzhou University of Technology, Lanzhou 730050, China. ${ }^{3}$ School of Mechanical and Electrical Engineering, Lanzhou University of Technology, Lanzhou 730050, China.

Received: 24 March 2020 Revised: 5 January 2021 Accepted: 25 May 2021 Published online: 09 June 2021 


\section{References}

[1] KVWong, A Hernandez. A review of additive manufacturing. ISRN Mechanical Engineering, 2012(2): 30-38.

[2] D Ding, Z Pan, D Cuiuri, et al. Wire-feed additive manufacturing of metal components: technologies, developments and future interests. International Journal of Advanced Manufacturing Technology, 2015, 81: 465-481.

[3] SW Williams, F Martina, A C Addison, et al. Wire + arc additive manufacturing. Materials Science \& Technology, 2016, 32(7): 641-647.

[4] IvánTabernero, A Paskual, P Álvarez, et al. Study on arc welding processes for high deposition rate additive manufacturing. Procedia CIRP, 2018, 68: 358-362.

[5] D Ding, Z Pan, D S Van, et al. Fabricating superior NiAl bronze components through wire arc additive manufacturing. Materials, 2016, 9(8): 652-664.

[6] J D Spencer, P M Dickens, C M Wykes. Rapid prototyping of metal parts by three-dimensional welding. Proceedings of the Institution of Mechanical Engineers Part B Journal of Engineering Manufacture, 1998, 212(3): 175-182.

[7] D Yang, G Wang, G Zhang. Thermal analysis for single-pass multi-layer GMAW based additive manufacturing using infrared thermography. Journal of Materials Processing Technology, 2017, 244: 215-224.

[8] X Chen, J Li, Z Huang, et al. Microstructure and mechanical properties of the austenitic stainless steel $316 \mathrm{~L}$ fabricated by gas metal arc additive manufacturing. Materials Science \& Engineering A, 2017, 703: 567-577.

[9] F Martina, J Mehnen, S W Williams, et al. Investigation of the benefits of plasma deposition for the additive layer manufacture of Ti-6Al-4V. Journal of Materials Processing Technology, 2012, 212(6): 1377-1386.

[10] S Jhavar, N K Jain, C P Paul. Development of micro-plasma transferred arc ( $\mu$-PTA) wire deposition process for additive layer manufacturing applications. Journal of Materials Processing Tech., 2014, 214(5): 1102-1110.

[11] E M Qureshi, A M Malik, N U Dar. Thermo-mechanical analysis of residual stresses in arc welded thin-walled cylinders. Proceedings of the 16th International Conference on Nuclear Engineering, Florida, USA, May 11-15, 2008 : 139-147.

[12] J Ding, P Colegrove, J Mehnen, et al. Thermo-mechanical analysis of wire and arc additive layer manufacturing process on large multi-layer parts. Computational Materials Science, 2011, 50(12): 3315-3322.

[13] D Ding, Z Pan, D Cuiuri, et al. A tool-path generation strategy for wire and arc additive manufacturing. International Journal of Advanced Manufacturing Technology, 2014, 73(4): 173-183.

[14] R Liu, Z Wang, Y Zhang, et al. A smooth toolpath generation method for laser metal deposition. Proceedings of the 27th Annual International Solid Freeform Fabrication Symposium, Texas, USA, August 7-9, 2016: 1038-1046.

[15] O H Petersen, D Burdakov, A V Tepikin. Process control and development in wire and arc additive manufacturing. Cranfield University, 2012, 30(3): 218-226.
[16] B Wu, D Ding, Z Pan, et al. Effects of heat accumulation on the arc characteristics and metal transfer behavior in Wire Arc Additive Manufacturing of Ti6Al4V. Journal of Materials Processing Technology, 2017, 250: 304-312.

[17] X Bai, P Colegrove, J Ding, et al. Numerical analysis of heat transfer and fluid flow in multilayer deposition of PAW-based wire and arc additive manufacturing. International Journal of Heat \& Mass Transfer, 2018, 124 504-516.

[18] N Kumar, P K Jain, P Tandon, et al. Toolpath generation for additive manufacturing using CNC milling machine. 3D Printing and Additive Manufacturing Technologies, 2018: 73-82. https://doi.org/10.1007/978981-13-0305-0_7

[19] D Ding, Z Pan, D Cuiuri, et al. A practical path planning methodology for wire and arc additive manufacturing of thin-walled structures. Robotics \& Computer Integrated Manufacturing, 2015, 34: 8-19.

[20] G Venturini, F Montevecchi, F Bandini, et al. Feature based three axes computer aided manufacturing software for wire arc additive manufacturing dedicated to thin walled components. Additive Manufacturing, 2018, 22: 643-657.

[21] J Xiong, G Zhang. Adaptive control of deposited height in GMAW-based layer additive manufacturing. Journal of Materials Processing Technology, 2014, 214(4): 962-968.

[22] H Dong, M Cong, Y Zhang, et al. Modeling and real-time prediction for complex welding process based on weld pool. International Journal of Advanced Manufacturing Technology, 2018, 96(5): 2495-2508.

[23] F Li, S Chen, ZWu, et al. Adaptive process control of wire and arc additive manufacturing for fabricating complex-shaped components. International Journal of Advanced Manufacturing Technology, 2018, 96(2): 1-9.

[24] Z Pan, D Ding, B Wu, et al. Arc welding processes for additive manufacturing: A review. Transactions on Intelligent Welding Manufacturing, 2017, 5(1): 3-24.

[25] W Gao, Y Zhang, D Ramanujan, et al. The status, challenges, and future of additive manufacturing in engineering. Computer-Aided Design, 2015, 69: 65-89.

[26] B Lu, W Zhao, Y Tang, et al. Investigation of the overlapping parameters of MPAW-based rapid prototyping. Rapid Prototyping Journal, 2006, 12(3): 165-172.

[27] Y Lu, S J Chen, Y Shi, et al. Double-electrode arc welding process: Principle, variants, control and developments. Journal of Manufacturing Processes, 2014, 16(1):93-108.

[28] K Li, Y M Zhang. Modeling and control of consumable double-electrode gas metal arc welding proceeding. Proceedings of the 17th International Federation of Automatic Control World Congress, Seoul, Korea, July 6-7, 2008: 994-999.

\section{Submit your manuscript to a SpringerOpen ${ }^{\circ}$ journal and benefit from:}

- Convenient online submission

- Rigorous peer review

- Open access: articles freely available online

- High visibility within the field

Retaining the copyright to your article

Submit your next manuscript at springeropen.com 